\title{
Prevalence and risk factors for selected canine vector-borne diseases in Greece
}

\author{
Athanasios Angelou', Athanasios I. Gelasakis ${ }^{2}$, Natalia Verde ${ }^{3}$, Nikola Pantchev ${ }^{4}$, Roland Schaper ${ }^{5}$, \\ Ramaswamy Chandrashekar ${ }^{6}$ and Elias Papadopoulos ${ }^{1 *}$
}

\begin{abstract}
Background: Canine vector-borne diseases (CVBDs) represent a wide group of diseases of major significance for canine health. In addition to their veterinary importance, many of these diseases are of great zoonotic concern, posing a risk of potential transmission to humans. To date, there has been scant knowledge regarding the prevalence, distribution and risk factors of CVBDs in Greece. Therefore, the objectives of the present study were to update the current knowledge on the seroprevalence of Dirofilaria immitis, Anaplasma spp., Ehrlichia spp. and Borrelia burgdorferi (sensu lato) in dogs in Greece and, furthermore, to assess possible environmental and any other risk factors associated with these infections. A total of 1000 apparently healthy and randomly selected dogs, presented in veterinary clinics, were involved at the national level ( $n=66$ municipalities). Serum samples were obtained from each individual dog and were tested using the SNAP ${ }^{\circledR} 4 D x^{\circledR}$ Plus kit from IDEXX Laboratories. Possible risk factors were assessed using binary regression models, including dogs' lifestyle, climatological parameters and the altitude of the region.
\end{abstract}

Results: Overall, $21.8 \%$ (95\% Cl: 19.4-24.5\%) of the sampled dogs were found to be seropositive to at least one of the four pathogens examined. The most prevalent pathogen was Ehrlichia spp. (12.5\%, 95\% Cl: 10.6-14.7) followed by D. immitis (9.0\%, 95\% Cl: 7.8-11.5) and Anaplasma spp. (6.2\%, 95\% Cl: 4.9-7.9). The lowest prevalence (0.1\%) was recorded for $B$. burgdorferi (s.l.) where only one dog was found to be positive. Among the examined risk factors, low mean temperature was found to increase the prevalence of Ehrlichia spp. $(P \leq 0.001)$ and Anaplasma spp. $(P \leq 0.001)$, while low minimum temperature increased the prevalence of $D$. immitis $(P \leq 0.001)$. In addition, low total annual rainfall had an effect of the prevalence of Ehrlichia spp. $(P \leq 0.01)$. Altitude also had a significant effect on the prevalence of $D$. immitis $(P \leq 0.05)$ and Anaplasma spp. $(P \leq 0.01)$.

Conclusions: To our knowledge, this is the first large-scale seroepidemiological study of CVBDs in Greece. It has been evidenced that environmental factors such as temperature, rainfall and altitude can influence the prevalence and distribution of CVBDs.

Keywords: Vector-borne, Dogs, Risk factors, Climate, Altitude, Temperature, Rainfall, Greece

\section{Background}

Canine vector-borne diseases (CVBDs) can significantly impact canine health status. The etiology of CVBDs is wide, including a variety of pathogens, i.e. protozoans, helminths, bacteria and viruses, all transmitted by hematophagous arthropods such as mosquitoes, ticks,

\footnotetext{
*Correspondence: eliaspap@vet.auth.gr

${ }^{1}$ Laboratory of Parasitology and Parasitic Diseases, School of Veterinary Medicine, Faculty of Health Sciences, Aristotle University of Thessaloniki, PO Box: 393, 54124 Thessaloniki, Greece

Full list of author information is available at the end of the article
}

fleas, lice and phlebotomine sandflies [1, 2]. CVBDs have a wide range of clinical manifestation, from asymptomatic cases to severe health implications, depending on the pathogenicity of the specific causative agent and the presence of single or co-infections, which complicates their diagnosis, control and treatment for veterinary practitioners [3, 4]. Moreover, animals with subclinical CVBDs infections are more susceptible to other infectious diseases $[5,6]$. In addition to their veterinary importance, many of these diseases are of major zoonotic concern, posing a risk of potential transmission to 
humans [3, 7]. Therefore, the control of these diseases is a challenging field with evident benefits for both animal and public health $[3,8]$. In this respect, Ehrlichia canis, Dirofilaria immitis, Anaplasma phagocytophilum and Borrelia burgdorferi are of great concern [4].

During recent decades, the worldwide distribution of CVBDs has been constantly changing [9]. This is attributed to a plethora of anthropogenic factors, including climate change, globalization, international transportation and trade, and the rapid growth of human, canine and wildlife reservoir populations [10]. Climate is a substantial factor considering the survival and spread of arthropod vectors and subsequently the distribution of CVBDs [9]. In particular, arthropod vectors and their life-cycles are strongly affected by environmental temperature. Apart from the life-cycle of vectors, the reproduction and survival rate of the parasitic and viral agents inside vectors and definitive hosts have also been found to be affected by environmental temperature [11].

Vectors (e.g. Aedes albopictus) and pathogens (e.g. Leishmania infantum, D. immitis) could expand or (re-)emerge due to climate change [12-15]. In Greece, according to the Intergovernmental Panel of Climate Change (IPCC), the climate is expected to evolve towards more tropical climates characterized by an extended dry and hot season [16], and this may affect the distribution of CVBDs [17] in the country.

According to relevant studies, many CVBDs have been reported in canine populations [18, 19], as well as in human populations in Greece [20-22]. However, the majority of the fore-mentioned studies have been focused on single species of pathogens and examined the situation in a restricted area and number of animals. Furthermore, none of these studies have assessed the relationship between climate and the seroprevalence of CVBDs in the country.

The aim of this study was to update the current state of knowledge on the seroprevalence of Ehrlichia spp., D. immitis, Anaplasma spp. and B. burgdorferi (s.l.), in Greece. In addition, we studied the effects of environmental and other risk factors on the seroprevalence of CVBDs in Greece.

\section{Methods}

\section{Study area}

At least one representative area from each municipality of the country was selected for sampling. This resulted in 66 locations similarly-spaced along the north-south and the east-west axes of the country for the sample collection. Among these areas there was a significant diversity of geographical and climate characteristics such as altitude, longitude, latitude, relative humidity, environmental temperature, total annual rainfall and wind speed.

\section{Animals and sample collection}

An overall population of 1000 dogs from 66 municipalities was included in the survey: 189 (18.9\%) dogs from central Greece; 188 (18.8\%) from Macedonia; 181 (18.1\%) from Aegean Islands; 150 (15.0\%) from Thrace; 116 (11.6\%) from Peloponnese; 55 (5.5\%) from Ionian Islands; 48 (4.8\%) from Crete; 44 (4.4\%) from Thessaly; and 29 (2.9\%) dogs from Epirus (Fig. 1).

All sampled dogs were randomly selected and apparently healthy. A blood sample was collected from each individual $\mathrm{dog}$ when visiting the veterinary clinic for annual vaccination or routine inspection. Blood was collected from the cephalic or jugular vein into vacutainer tubes without anticoagulant and stored in the refrigerator for a maximum of $24 \mathrm{~h}$ until centrifugation. Samples were centrifuged at $1300-1800 \times g$ for $20 \mathrm{~min}$, and then serum was separated from the clot. Serum samples were stored at $-20^{\circ} \mathrm{C}$ until further assayed.

After sample collection, data regarding the characteristics of the dogs were collected using a structured, casespecific questionnaire including information about age, sex, breed, lifestyle (outdoors, indoors) of the dog and information about the last antiparasitic treatment (endoand/or ectoparasiticides active against vectors or vectorborne pathogens, i.e. milbemycin, fipronil, permethrin, etc.), as presented in Table 1. All dogs participating in the study were apparently healthy at physical examination, not infested with ectoparasites and older than 6 months. The study lasted one year, from the 1st of January 2016 until the 31st of December 2016.

\section{Climatological and altitude data}

For each of the studied regions climatological data were collected including mean, minimum and maximum environmental temperature $\left({ }^{\circ} \mathrm{C}\right)$, mean humidity (\%), total annual rainfall $(\mathrm{mm})$ and mean wind speed (knots). Meteorological data were acquired from two climatological databases, namely the Hellenic National Meteorological Services (HNMS) and the "Meteo View" platform. The HNMS is the official government agency responsible for the weather forecast and observations at the national level. The "Meteo View" platform is a web-based geographical information system (GIS) tool created and hosted by the "Meteo" weather service. It was made for monitoring and analyzing the meteorological station network set up by Meteo, the Institute of Environmental Research and Sustainable Development (IERSD) and the National Observatory of Athens (NOA). For each studied region, the nearest meteorological station was selected, and its data were used for further analyses. Mean values for each metric were obtained from HNMS and supplemented by the "Meteo View" when it was necessary. The mean values obtained from these metrics were as 

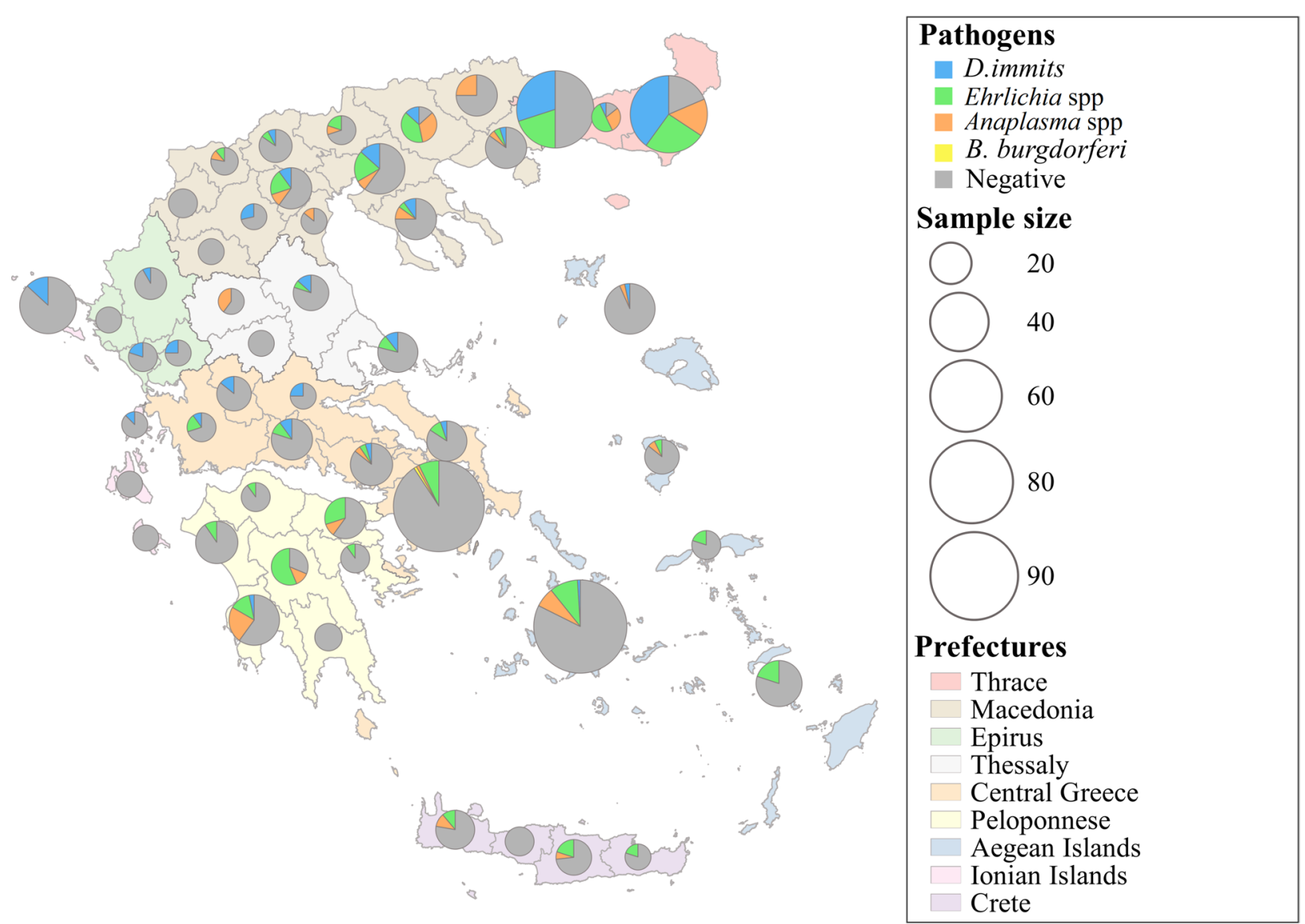

Fig. 1 Geographical distribution of seropositive dogs for CVBDs in Greece

follows: $15.9{ }^{\circ} \mathrm{C},-5.5{ }^{\circ} \mathrm{C}$ and $38.3{ }^{\circ} \mathrm{C}$ for mean, minimum and maximum environmental temperature, respectively, $69.7 \%$ for mean relative humidity, $554 \mathrm{~mm}$ for total annual rainfall and 10.7 knots for mean wind speed.

The altitude data of the studied regions were derived from a digital elevation model (DEM) and data collected by NASA's Shuttle Radar Topography Mission (SRTM) which provides an accuracy of approximately $\pm 1.73 \mathrm{~m}$. This accuracy level has been considered sufficient for similar studies and has already been used in order to extract geographical information [23, 24]. The altitude measurements were taken from points on the map which represented the exact place of sampling. Three altitudezones were considered: 0-100 metres above sea level (masl); 101-400 masl; and 401-900 masl.

\section{Serological analysis}

Serum samples were tested using a rapid enzyme-linked immunosorbent assay (ELISA) kit $\left(\mathrm{SNAP}^{\circledR} 4 \mathrm{Dx}{ }^{\circledR}\right.$ Plus Test Kit, IDEXX Laboratories, Inc, Westbrook, ME, USA), according to the manufacturer instructions. Two spots are impregnated respectively with a specific peptide antigen of B. burgdorferi (s.l.) (C6 peptide, derived from the IR6 region within the Borrelia membrane protein VlsE; [25]) and E. canis (peptides from p30 and p30-1 outer membrane proteins; cross-reactive with Ehrlichia chaffeensis; [26]). The device additionally detects antibodies to E. ewingii (peptide derived from p28 outer surface protein family; [27]). The $D$. immitis analyte is derived from two antibodies (one for capture and the other for detection) specific to heartworm antigens, which are primarily produced by adult females. This in-clinic test detects specific antibodies to $A$. phagocytophilum/A. platys (peptide from the major surface protein $\mathrm{p} 44 /$ MSP2; [27]). In contrast to the whole-cell antigen present on $A$. phagocytophilum IFA slides, no genus level crossreaction between Anaplasma and Ehrlichia is observed within this device based on the utilization of specific peptides [28]. The respective sensitivity and specificity of the test system are 93.2 and $99.2 \%$ for $A$. phagocytophilum, 89.2 and $99.2 \%$ for $A$. platys, 96.7 and $98.8 \%$ for $B$. burgdorferi (s.l.), 97.8 and $92.3 \%$ for E. canis, and 98.9 and 99.3\% for D. immitis. Furthermore, a cross-reactivity of $E$. canis antigens with anti-E. chaffeensis antibodies was 
shown. Due to documented cross-reactivity between $A$. phagocytophilum and A. platys, as well as the reactivity to E. canis, E. chaffeensis and E. ewingii [27], we refer to Anaplasma spp. and Ehrlichia spp. in the results of the present study (as isolates were not identified to the species level).

\section{Data handling and statistical analysis}

Data were recorded in a Microsoft Excel spreadsheet and imported into IBM SPSS Statistics v.23.0. for the subsequent statistical analyses. The prevalence of parasitic infections was defined as the proportion of positive animals to the total number of the examined animals and the $95 \%$ confidence intervals $(\mathrm{CI})$ of the prevalence values were estimated using the Wilson score interval method. Stepwise binary logistic regression models were used to assess the effects of possible risk factors [age, sex, habitat, use, last antiparasitic treatment, altitude, environmental temperature (mean, minimum and maximum), mean humidity, total annual rainfall and wind speed] on the likelihood that a dog is infected with Ehrlichia spp., D. immitis and Anaplasma spp.

A forward stepwise selection procedure of the variables was followed and only predictors which had a significant effect $(P \leq 0.05)$ on each individual parasitic infection were used for the final models. According to this, the likelihood of (i) Ehrlichia spp., (ii) D. immitis, and (iii) Anaplasma spp. infection were estimated using as predictors the regression coefficients of (i) habitat use, last antiparasitic treatment, mean temperature and total annual rainfall, (ii) altitude, last antiparasitic treatment and minimum temperature, and (iii) altitude, last antiparasitic treatment and mean temperature.

Statistical significance of individual predictors was tested using the Wald Chi-square statistic of their regression coefficients $(\beta \mathrm{s})$. The Hosmer-Lemeshow $(\mathrm{H}-\mathrm{L})$ test, Cox and Snell $R^{2}$ and Nagelkerke $R^{2}$ indices were also calculated to assess the goodness-of-fit for each individual model.

\section{Results}

The distribution of the sampled dogs according to climatological data and the altitude of the studied areas are summarized in Table 1.

\section{Seroprevalence of CVBDs in the studied dog population} Overall, $21.8 \%$ (218/1000, 95\% CI: $19.4-24.5 \%)$ of the sampled dogs were found to be seropositive to at least one of the four pathogens examined in this present study (Table 2). Moreover, the proportion of dogs that were seropositive against one, two or three parasites was 16.5\% (165/1000, 95\% CI: 14.3-18.9\%), 4.7\% (47/1000, 95\% CI: $3.6-6.2 \%)$ and $0.6 \%(6 / 1000,95 \%$ CI: $0.3-1.3)$,
Table 1 Distribution of the dog population ( $n=1000$ dogs) according to the studied parameters

\begin{tabular}{|c|c|c|}
\hline Parameter & Level & $\begin{array}{l}\text { No. of studied } \\
\text { dogs }\end{array}$ \\
\hline \multirow[t]{4}{*}{ Age (years) } & $<1$ & 69 \\
\hline & $1-3$ & 374 \\
\hline & $3-5$ & 279 \\
\hline & $>5$ & 278 \\
\hline \multirow[t]{2}{*}{ Sex } & Male & 468 \\
\hline & Female & 532 \\
\hline \multirow[t]{2}{*}{ Lifestyle } & Outdoors & 807 \\
\hline & Indoors & 193 \\
\hline \multirow[t]{4}{*}{ Breed } & Crossbreeds & 648 \\
\hline & English Setter & 79 \\
\hline & German Shepherd & 49 \\
\hline & Other purebred breeds & 224 \\
\hline \multirow{5}{*}{$\begin{array}{l}\text { Last antiparasitic treatment } \\
\text { (months passed) }\end{array}$} & No treatment & 290 \\
\hline & $<3$ & 457 \\
\hline & $3-6$ & 173 \\
\hline & $6-12$ & 54 \\
\hline & $>12$ & 26 \\
\hline \multirow{2}{*}{$\begin{array}{l}\text { Mean environmental tem- } \\
\text { perature }\left({ }^{\circ} \mathrm{C}\right)\end{array}$} & $>15.9$ & 781 \\
\hline & $\leq 15.9$ & 219 \\
\hline \multirow{2}{*}{$\begin{array}{l}\text { Minimum environmental } \\
\text { temperature }\left({ }^{\circ} \mathrm{C}\right)\end{array}$} & $>-5.5$ & 665 \\
\hline & $\leq-5.5$ & 335 \\
\hline \multirow{2}{*}{$\begin{array}{l}\text { Maximum environmental } \\
\text { temperature }\left({ }^{\circ} \mathrm{C}\right)\end{array}$} & $>38.3$ & 348 \\
\hline & $\leq 38.3$ & 652 \\
\hline \multirow[t]{2}{*}{ Mean humidity (\%) } & $>69.7$ & 456 \\
\hline & $\leq 69.7$ & 544 \\
\hline \multirow[t]{2}{*}{ Total annual rainfall (mm) } & $>554$ & 701 \\
\hline & $\leq 554$ & 299 \\
\hline \multirow[t]{2}{*}{ Mean wind speed (knots) } & $>10.7$ & 127 \\
\hline & $\leq 10.7$ & 873 \\
\hline \multirow[t]{3}{*}{ Altitude (masl) } & $0-100$ & 811 \\
\hline & $101-400$ & 123 \\
\hline & $401-900$ & 66 \\
\hline
\end{tabular}

Abbreviation: masl, metres above sea level

respectively (Table 2). Overall, the most prevalent canine vector-borne pathogen was Ehrlichia spp. (12.5\%, 125/1000, 95\% CI: 10.6-14.7\%) followed by D. immitis (9.0\%, 90/1000, 95\% CI: 7.8-11.5\%) and Anaplasma spp. (6.2\%, 62/1000, 95\% CI: 4.9-7.9\%); the lowest prevalence was recorded for B. burgdorferi (s.l.) where only one dog was found to be positive $(0.1 \%)$. The detailed epizootiological map deriving from our results is presented in Fig. 1.

Risk factors associated to CVBD seroprevalence

Table 3 summarizes the risk factors for CVBDs and their effects on seropositivity status. For Ehrlichia spp., 
animals that lived outdoors were more likely to be seropositive to Ehrlichia spp. in comparison with those living indoors $(P=0.013$, OR: $2.3,95 \%$ CI: $1.2-4.4)$. Moreover, companion dogs were more likely to be seropositive for Ehrlichia spp. than hunting dogs $(P=0.002$, OR: 2.6, 95\% CI: 1.4-4.6). Additionally, the likelihood of Ehrlichia spp. seropositivity was higher for the animals that have not received antiparasitic treatment (endo- and/or ectoparasiticides active against vectors or vector-borne pathogens, i.e. milbemycin, fipronil, permethrin, etc.) for 12 months prior to sampling, when compared to those that had never received antiparasitic treatment $(P=0.03$, OR: $2.7,95 \%$ CI: $1.1-6.7)$, those that had received treatment in the last 6 to 12 months $(P=0.007$, OR: $5.6,95 \%$ CI: $1.6-19.6), 3$ to 6 months ( $P=0.001$, OR: $5.1,95 \%$ CI: 1.9-13.9) and less than 3 months $(P=0.0001$, OR: 5.6 , 95\% CI: 2.3-13.9). Regarding the climatological conditions, the likelihood of Ehrlichia spp. seropositivity was higher for dogs living in areas with a mean temperature $<15.9^{\circ} \mathrm{C}(P=0.001$, OR: $2.2,95 \% \mathrm{CI}: 1.4-3.5)$ in comparison to dogs living in areas with mean temperature $\geq 15.9$ ${ }^{\circ} \mathrm{C}$. Similarly, dogs that were living in areas with lower total annual rainfall were more likely to be seropositive to Ehrlichia spp. when compared to those animals that were living in areas with higher total annual rainfall $(P=0.004$, OR: $2.1,95 \%$ CI: $1.3-3.5)$. In the case of D. immitis infection, dogs that were living in areas with an altitude of 0-100 masl were more likely to be infected when compared to dogs living in areas with an altitude of 401-900 masl ( $P=0.019$, OR: $3.2,95 \%$ CI: $1.2-8.5)$. Additionally, the likelihood of $D$. immitis seropositivity was higher for the animals that had not received antiparasitic treatment for more than 12 months comparing to those that had received treatment in the last 3 months $(P<0.0001$, OR: 5.8, 95\% CI: 2.2-15.1) and those that had received

Table 2 Number and prevalence of canine vector-borne infections and co-infections in the studied dog population ( $n=1000$ dogs) in Greece

\begin{tabular}{|c|c|c|}
\hline Pathogen & $\begin{array}{l}\text { No. of infected } \\
\text { dogs }\end{array}$ & $\begin{array}{l}\text { Prevalence } \\
\text { (\%) }\end{array}$ \\
\hline Dirofilaria immitis & 59 & 5.9 \\
\hline Ehrlichia spp. & 79 & 7.9 \\
\hline Anaplasma spp. & 27 & 2.7 \\
\hline $\begin{array}{l}\text { Dirofilaria immitis + Ehrlichia } \\
\text { spp. + Anaplasma spp. }\end{array}$ & 5 & 0.5 \\
\hline Dirofilaria immitis + Ehrlichia spp. & 19 & 1.9 \\
\hline Dirofilaria immitis + Anaplasma spp. & 7 & 0.7 \\
\hline Ehrlichia spp. + Anaplasma spp. & 21 & 2.1 \\
\hline $\begin{array}{l}\text { Ehrlichia spp. + Anaplasma spp. + Bor- } \\
\text { relia burgdorferi (s.l.) }\end{array}$ & 1 & 0.1 \\
\hline Total & 218 & 21.8 \\
\hline
\end{tabular}

treatment in the last 3 to 6 months $(P<0.0001$, OR: 7.6, 95\% CI: 2.5-23.8). Moreover, the likelihood of $D$. immitis seropositivity was higher for dogs living in areas with a minimum temperature $<-5.5{ }^{\circ} \mathrm{C}$ in comparison to dogs living in regions with a minimum temperature $\geq-5.5^{\circ} \mathrm{C}$ $(P<0.0001$, OR: $4.5,95 \%$ CI: $2.7-7.5)$. The effects of the risk factors on Anaplasma spp. seropositivity status are presented in Table 3. The likelihood of Anaplasma spp. seropositivity was higher for dogs living in areas with a mean temperature $<15.9{ }^{\circ} \mathrm{C}$ when compared to those dogs living in areas with mean temperature $\geq 15.9{ }^{\circ} \mathrm{C}$ $(P<0.0001$, OR: $4.2,95 \%$ CI: $2.3-7.8)$. Moreover, dogs that were sampled from areas with an altitude of $0-100$ masl were more likely to be seropositive to Anaplasma spp. in comparison with dogs living in areas with an altitude of $401-900$ masl $(P=0.010$, OR: $7.1,95 \% \mathrm{CI}$ : 1.6-31.5). Finally, the likelihood of Anaplasma spp. seropositivity was higher for the animals that had never received any kind of antiparasitic treatment (endo- and/ or ectoparasiticides active against vectors or vectorborne pathogens, i.e. milbemycin, fipronil, permethrin, etc.) compared to the those that had received antiparasitic treatment in the last 3 to 6 months $(P=0.013$, OR: 3.5, 95\% CI: 1.3-9.3).

\section{Discussion}

CVBDs are of major importance for veterinarians as well as for public health practitioners and constitute a field of increased scientific interest worldwide. The primary aim of this multicentric study was to assess the seroprevalence of CVBDs in Greece and investigate possible relationships between these infections, climate conditions and altitude. To the best of the authors' knowledge, this is the first study conducted in Greece in order to assess the seroprevalence of CVBDs in canine population, which includes a large sample derived from each prefecture of the country and thus generates valuable and resilient data.

Overall, according to our results the recorded prevalence of CVBDs in dogs from Greece was high, with $21.8 \%$ of the sampled dogs being seropositive to at least one of the tested pathogens. Specifically, Ehrlichia spp. $(12.5 \%)$ were the most prevalent canine vector-borne pathogens followed by $D$. immitis $(9.0 \%)$ and Anaplasma spp. (6.2\%); the lowest prevalence was detected for $B$. burgdorferi (s.l.) (0.1\%). Correspondingly, previous studies have reported high prevalence estimates of CVBDs in other European countries, even though various diagnostic methods were used. In neighboring countries, such as Bulgaria and northeastern Turkey, studies have demonstrated a high prevalence of CVBDs with overall percentages of 64.7 and $48.9 \%$, respectively [25, 29], whereas in Italy and Romania the overall prevalence rates 
Table 3 P-values, odds ratios and 95\% Cl for odds ratios, of the predictor variables used in Ehrlichia spp., Dirofilaria immitis and Anaplasma spp. models

\begin{tabular}{|c|c|c|c|}
\hline Variable & $P$-value & Odds ratio & $95 \% \mathrm{Cl}$ \\
\hline \multicolumn{4}{|l|}{ Ehrlichia spp. } \\
\hline Habitat, outdoors & 0.013 & 2.287 & $1.193-4.383$ \\
\hline Habitat, indoors & Ref. & & \\
\hline Use, hunting & 0.002 & 0.392 & $0.217-0.708$ \\
\hline Use, companion & Ref. & & \\
\hline Last antiparasitic treatment, none & 0.030 & 0.370 & $0.150-0.910$ \\
\hline Last antiparasitic treatment $<3$ months & $<0.0001$ & 0.179 & $0.072-0.442$ \\
\hline Last antiparasitic treatment 3-6 months & 0.001 & 0.195 & $0.072-0.525$ \\
\hline Last antiparasitic treatment 6-12 months & 0.007 & 0.178 & $0.051-0.625$ \\
\hline Last antiparasitic treatment $>12$ months & Ref. & & \\
\hline Mean temperature $<15.9^{\circ} \mathrm{C}$ & 0.001 & 2.171 & $1.364-3.457$ \\
\hline Mean temperature $\geq 15.9^{\circ} \mathrm{C}$ & Ref. & & \\
\hline Total annual rainfall $<554 \mathrm{~mm}$ & 0.004 & 2.114 & $1.267-3.528$ \\
\hline Total annual rainfall $\geq 554 \mathrm{~mm}$ & Ref. & & \\
\hline Constant & 0.001 & 0.151 & \\
\hline \multicolumn{4}{|l|}{ Dirofilaria immitis } \\
\hline Altitude 0-100 masl & 0.019 & 3.213 & $1.210-8.534$ \\
\hline Altitude 101-400 masl & 0.556 & 1.463 & $0.412-5.202$ \\
\hline Altitude 401-900 masl & Ref. & & \\
\hline Last antiparasitic treatment, none & 0.072 & 0.442 & $0.181-1.077$ \\
\hline Last antiparasitic treatment $<3$ months & $<0.0001$ & 0.173 & $0.066-0.457$ \\
\hline Last antiparasitic treatment 3-6 months & $<0.0001$ & 0.131 & $0.042-0.407$ \\
\hline Last antiparasitic treatment 6-12 months & 0.746 & 0.837 & $0.286-2.449$ \\
\hline Last antiparasitic treatment $>12$ months & Ref. & & \\
\hline Minimum temperature $<-5.5^{\circ} \mathrm{C}$ & $<0.0001$ & 4.469 & $2.667-7.489$ \\
\hline Minimum temperature $\geq-5.5^{\circ} \mathrm{C}$ & Ref. & & \\
\hline Constant & 0.001 & 0.151 & \\
\hline \multicolumn{4}{|l|}{ Anaplasma spp. } \\
\hline Altitude 0-100 masl & 0.010 & 7.126 & $1.614-31.469$ \\
\hline Altitude 101-400 masl. & 0.311 & 2.395 & $0.443-12.958$ \\
\hline Altitude 401-900 masl & Ref. & & \\
\hline Last antiparasitic treatment $<3$ months & 0.104 & 0.598 & $0.322-1.111$ \\
\hline Last antiparasitic treatment 3-6 months & 0.013 & 0.288 & $0.108-0.772$ \\
\hline Last antiparasitic treatment 6-12 months & 0.085 & 0.168 & $0.022-1.281$ \\
\hline Last antiparasitic treatment $>12$ months & 0.998 & 0.000 & 0.000 \\
\hline Last antiparasitic treatment, none & Ref. & & \\
\hline Mean temperature $<15.9^{\circ} \mathrm{C}$ & $<0.0001$ & 4.242 & $2.302-7.820$ \\
\hline Mean temperature $\geq 15.9^{\circ} \mathrm{C}$ & Ref. & & \\
\hline Constant & $<0.0001$ & 0.012 & \\
\hline
\end{tabular}

Abbreviations: masl, metres above sea level; $\mathrm{Cl}$, confidence interval; Ref., reference category

were comparatively lower, i.e. 10.3 and $11.3 \%$ respectively $[30,31]$. Other studies from the Balkan Peninsula have indicated an overall prevalence of CVBDs ranging from $25.7 \%$ in Croatia to $25.1 \%$ in Albania [32, 33]. Higher prevalence rates have been observed in Spain (37.1\%) [34] and Portugal (66\%) [35]. In some of the aforementioned studies, the results reflect the simultaneous presence of other pathogens, i.e. Leishmania spp.

Among the examined vector-borne pathogens, Ehrlichia spp. was found to be the most common (12.5\%). Ehrlichiosis, apart from its veterinary importance, is of public health concern since some Ehrlichia species can also infect 
humans [36, 37]. To the best of our knowledge, prior to the present study there were no data available regarding the prevalence of Ehrlichia spp. in canine populations in Greece. Contrarily, there are some clinical studies reporting several cases of Ehrlichia spp. natural infections in dogs [38-41]. According to our findings, the likelihood of seropositivity to Ehrlichia spp. was associated mainly with the lifestyle of dogs and the antiparasitic scheme followed by the owner. First, dogs that were living outdoors had a higher possibility of being seropositive to Ehrlichia spp. when compared to those living indoors (c.2.3 times, $P \leq 0.05)$. This result can be attributed to the fact that dogs living outdoors have an increased chance of being exposed to the natural environment of the brown dog tick Rhipicephalus sanguineus (s.l.), which is the main vector of this pathogen and also the dominant tick species in dogs in Greece [42]. Lifestyle seems to have a significant effect on the seroprevalence of Ehrlichia spp. but not on the seroprevalence of the other studied tick-borne pathogens. A possible explanation relies to the fact that Ehrlichia spp. was the most prevalent pathogen and therefore the likelihood of its transmission is probably higher than that of the other examined tick-borne pathogens. Secondly, we found that that companion dogs had a greater chance of being seropositive to Ehrlichia spp. when compared to hunting dogs (c.2.6 times, $P=0.002)$. Parameters that could explain this finding include age and health status of the studied dogs. Hunting dogs are working dogs and hence they are mostly young dogs with a good health status which is necessary for being capable of hunting and also better prophylactically protected. When they grow older usually, they are donated and afterwards they are kept as companion dogs. Companion dogs, on the other hand, do not have any limitations regarding age or health status. Furthermore, it was found that dogs that did not receive frequent antiparasitic treatment tended to be seropositive to Ehrlichia spp. when compared to the animals that received them on a regular basis. As expected, the present result indicates that animals that received few antiparasitic treatments (including ectoparasiticides, i.e. fipronil and permethrin) were more likely to be infested by ticks and therefore it underlines the necessity of prevention against ectoparasites. In addition to the individual parameters of the dog, we also assessed environmental parameters as confounding factors. Nonetheless, a confounding effect regarding the region of the collected samples could be possible. In any case, comparisons between the 66 municipalities included in the sampling campaign was not within the scope of the present study and hence we selected not to use the fixed effect of region for the statistical analyses. Instead, we decided to assess climatic conditions (which are significant descriptors of the region) as possible risk factors. Under this perspective, it is possible to enhance the applicability of the results in other cases and regions where a similar climate exists. Regarding climatological conditions, surprisingly, it was demonstrated that dogs that were living in areas with a mean temperature $<15.9^{\circ} \mathrm{C}$ were more likely to be seropositive to Ehrlichia spp. than dogs living in areas with a mean temperature $\geq 15.9^{\circ} \mathrm{C}(c .2 .2$ times, $P=0.001)$. The exposure to extreme cold temperatures has a significant harmful effect on the development of $R$. sanguineus (s.l.) [43]. However, in Greece the climate remains typical mild Mediterranean, even in regions with a mean temperature $<15.9^{\circ} \mathrm{C}$, which favors the development of ticks. Moreover, we found that there is an effect of the total annual rainfall in the seroprevalence of Ehrlichia spp.: dogs that were living in dry areas with a low total annual rainfall $<554 \mathrm{~mm}(c .2 .1$ times, $P=0.004)$ were more likely to be seropositive to Ehrlichia spp. when compared to the animals that were living in wetter areas with a total annual rainfall $\geq 554 \mathrm{~mm}$. Similar results have been previously reported in a study in Brazil where dogs were more likely to be infested by $R$. sanguineus ticks in drier environments [44]. This could be linked to the fact that $R$. sanguineus ticks are better adapted to drier climates when compared to other tick species, such as Ixodes ricinus, which prefer wetter climates [45].

The second most frequent canine vector-borne pathogen detected in our study was $D$. immitis with an overall antigen seropositivity of $9.0 \%$. Dirofilaria immitis, widely known as the canine heartworm, is a filarial nematode transmitted by mosquitoes (Culex spp., Aedes spp. and Anopheles spp.) acknowledged to be the causative agent of cardiopulmonary dirofilariosis in dogs (heartworm disease) [46]. Dirofilaria immitis can also cause pulmonary dirofilariosis in humans, thus resulting in public health implications [47]. Many European countries, including Greece, are enzootic for this disease [18, 48]. Previous surveys from Greece have reported similar results; however, these were not large-scale studies and cannot be considered representative of the situation at a national level [18, 49, 50]. Additionally, dirofilariosis has also been previously reported in humans in Greece, a fact that underscores its zoonotic potential in the country [51, 52]. Nowadays, $D$. repens attracts more scientific interest as an emerging zoonotic agent than D. immitis. It is likely that in the past Dirofilaria species in humans were not always correctly identified and remained underdiagnosed at species level [53]. According to our results, the likelihood of antigen detection of $D$. immitis was associated mainly with the last antiparasitic treatments (i.e. milbemycin, permethrinor, other antiparasitics with repellent or larvicide activity against Dirofilaria spp.) of the examined animals. It can be concluded that unprotected animals are more susceptible to vector-borne infections. Therefore, the demand for frequent and effective chemoprophylaxis, for all dogs, all year round and regardless 
of the occurrence of infection should be emphasized. Moreover, it should be stressed that prevention for Dirofilaria infections is essential from both a veterinary and public health perspective. Altitude was found to be associated with $D$. immitis infection: dogs living in regions with a low altitude of 0-100 masl were more susceptible to dirofilariosis compared to dogs living in areas with a high altitude (401-900 masl). Mountainous regions with high altitude have low mean temperatures all year round and fewer water catchments, wetlands and valleys, which makes them unfavorable for the development of mosquitoes and, hence, the spreading of the disease. Similar results indicating this inversely proportional relationship between altitude and distribution of a mosquito-borne disease have been reported for malaria [54]. The likelihood of $D$. immitis seropositivity was also associated with the minimum temperature of the region of origin of the studied dogs. Surprisingly, our results indicate that dogs that were living in areas with a minimum temperature $<-5.5^{\circ} \mathrm{C}$ had a higher probability of being $D$. immitis-antigen-positive in comparison to those that were living in areas with a minimum temperature $\geq-5.5^{\circ} \mathrm{C}$. However, it has already been stated from previous studies that there is a northward geographical distribution of D. immitis in Greece [18], something that corresponds to our results, as the majority of regions with low minimum temperature are located in the northern part of the country. This finding can be easily explained by the increased population of mosquitoes in the northern parts of Greece [55], where water retention sites, ponds and agricultural valleys are more common. In the present study, the association between climatological conditions, altitude and seroprevalence of canine dirofilariosis has been assessed for the first time in Greece. Notably, in the present study, cases of canine dirofilariosis were reported in the Cyclades Islands and Southern Peloponnese, thus indicating a possible spread southward.

The third examined canine vector-borne pathogen group were Anaplasma species. Anaplasma platys, transmitted by $R$. sanguineus (s.l.), infects the platelets and is considered as the etiological agent of infectious canine cyclic thrombocytopenia [56, 57]. Conversely, $A$. phagocytophilum, transmitted by Ixodes ricinus ticks, infects white blood cells, mainly neutrophils, causing granulocytic anaplasmosis in dogs [58]. Additionally, $A$. phagocytophilum could be pathogenic for humans with potential zoonotic implications [58]. Due to their molecular similarity and cross-reactions, it is almost impossible to differentiate A. platys and A. phagocytophilum using serological analysis [59] while mixed infections are possible [60]. It was found that the overall prevalence of $A$. platys and/or A. phagocytophilum seropositivity was $6.2 \%$. Data regarding the seroprevalence of Anaplasma spp. in the canine population in Greece were scarce except for some sporadic reported cases of $A$. phagocytophilum infections $[19,61]$. A recent study reported $A$. platys in $R$. sanguineus ticks in Greece [42]. There are some studies considering human anaplasmosis due to A. phagocytophilum highlighting the zoonotic potential of this disease in Greece [20,62,63]. According to the results obtained for Ehrlichia spp. and D. immitis, a negative correlation between the seropositivity to Anaplasma spp. and the time of the last antiparasitic (i.e. fipronil, permethrin, etc.) treatment of the dog was reported. This result underlines that unprotected animals are at a significant risk of acquiring any of the CVBDs. Moreover, the mean environmental temperature poses a significant risk factor for the seropositivity to Anaplasma spp. As is the case for Ehrlichia spp., mean environmental temperature acts as a crucial factor for the development and distribution of ticks thereby affecting the distribution of tick-borne diseases, including anaplasmosis. Altitude of a region significantly affects the likelihood of seropositivity to Anaplasma spp., which is consistent with a previous study, where it was indicated that canine anaplasmosis due to A. phagocytophilum is an altitude-dependent disease [64].

In the present study the seropositivity to the spirochete B. burgdorferi was assessed. Borrelia burgdorferi (s.l.) complex includes at least 19 species and is transmitted mainly by ticks of the genus Ixodes [26]. Borrelia burgdorferi is the primary agent that causes Lyme borreliosis in dogs and humans [65]. Dogs are naturally exposed to tick infestations, may act as reservoirs, and consequently play a significant role to the transmission of Lyme disease to humans [66]. Although Lyme borreliosis in humans has been previously reported in Greece $[67,68]$ this is the first time a seropositive $\operatorname{dog}$ for $B$. burgdorferi has been identified. It should be noted that the prevalence of infection detected in dogs is low. Correspondingly, the incidence of human borreliosis in Greece is the lowest among other European countries [69]. The above can be attributed to the fact that the main tick species that infests dogs in Greece is the brown dog tick ( $R$. sanguineus), which does not transmit B. burgdorferi. On the other hand, I. ricinus that is the main vector of $B$. burgdorferi is very rare in Greece [42]. As expected, in northern countries of Europe where the prevalence of I. ricinus is high, the occurrence of Lyme borreliosis in dogs is higher.

\section{Conclusions}

Our results suggest that animals living outdoors and receiving only occasionally or no antiparasitic treatments are prone to infections with canine vector-borne 
pathogens. These findings highlight the significance and the urgent need for appropriate antiparasitic treatments, especially for those dogs living mostly outdoors. Additionally, it is essential to underline that early diagnosis by using quick with high sensitivity and specificity diagnostic tests such as $\mathrm{SNAP}^{\circledR} 4 \mathrm{Dx}^{\circledR}$ Plus, as well as early intervention of CVBDs could improve the expected prognosis, especially in life-threatening diseases. Finally, our work represents the first attempt to demonstrate the relationships between the seroprevalence of CVBDs and climatological conditions, including altitude. Among the examined climatologic conditions, mean and minimum temperature, rainfall and altitude can influence the prevalence and distribution of CVBDs.

\section{Abbreviations}

CVBDs: canine vector-borne diseases; Cl: confidence interval; s.l.: sensu lato; HNMS: Hellenic National Meteorological Services; masl: meters above sea level.

\section{Acknowledgements}

The authors would like to thank the Hellenic National Meteorological Services (HNMS) for providing the climatologic data, and also all the dog owners and veterinarians who collaborated in this study.

\section{Authors' contributions}

AA: parasitological methods and preparation of the manuscript. GAl: statistical analyses and preparation of the manuscript. NV: data handling and map. NP and RC: critical review of the manuscript. RS and EP: study design and critical review of the manuscript. All authors read and approved the final manuscript.

\section{Funding}

The study was funded by Bayer Animal Health, Leverkusen Germany. The diagnostic kits were kindly donated by IDEXX Laboratories Inc., Westbrook. USA

\section{Availability of data and materials}

Data supporting the conclusions of this article are included within the article.

\section{Ethics approval and consent to participate}

The study was conducted in compliance with the national animal welfare regulations. The applied diagnostic veterinary procedures are not within the context of relevant EU legislation for animal experimentations (Directive 86/609/EC) and may be performed in order to diagnose animal diseases and improve animal welfare. No suffering was caused during sample collection. Consent was given by owners or registered veterinarians (private, public or municipality, depending on the case). Owners consent was obtained prior to collection of samples according to standard procedures adopted by the involved clinics.

\section{Consent for publication}

Not applicable.

\section{Competing interests}

RS is employed by Bayer but the survey was purely epidemiological without any product use. RC and NP are employed by IDEXX but were not involved in the diagnostic procedure. AA, AIG, NV and EP declare that they have no competing interests.

\footnotetext{
Author details

${ }^{1}$ Laboratory of Parasitology and Parasitic Diseases, School of Veterinary Medicine, Faculty of Health Sciences, Aristotle University of Thessaloniki, PO Box: 393, 54124 Thessaloniki, Greece. ${ }^{2}$ Laboratory of Farm Animal Anatomy and Physiology, Department of Animal Science and Aquaculture, School of Agricultural Production, Infrastructure and Environment, Agricultural University of Athens, 11855 lera Odos, Greece. ${ }^{3}$ Laboratory of Photogrammetry and Remote Sensing, Department of Cadastre, Photogrammetry
}

and Cartography, Faculty of Rural and Surveying Engineering, Aristotle University of Thessaloniki, 54124 Thessaloniki, Greece. ${ }^{4}$ IDEXX Laboratories, 71636 Ludwigsburg, Germany. ${ }^{5}$ Bayer Animal Health GmbH, 51368 Leverkusen, Germany. ${ }^{6}$ IDEXX Laboratories Inc., Westbrook, ME 04092, USA.

Received: 22 January 2019 Accepted: 29 May 2019

Published online: 03 June 2019

\section{References}

1. Otranto D, Dantas-Torres F, Breitschwerdt EB. Managing canine vector-borne diseases of zoonotic concern: part one. Trends Parasitol. 2009;25:157-63.

2. Beugnet F, Marie JL. Emerging arthropod-borne diseases of companion animals in Europe. Vet Parasitol. 2009;163:298-305.

3. Otranto D, Dantas-Torres F, Breitschwerdt EB. Managing canine vector-borne diseases of zoonotic concern: part two. Trends Parasitol. 2009:25:228-35.

4. Day MJ. The immunopathology of canine vector-borne diseases. Parasit Vectors. 2011:4:48.

5. Billeter SA, Levy MG, Chomel BB, Breitschwerdt EB. Vector transmission of Bartonella species with emphasis on the potential for tick transmission. Med Vet Entomol. 2008;22:1-15.

6. Perez C, Maggi RG, Diniz PP, Breitschwerdt EB. Molecular and serological diagnosis of Bartonella infection in 61 dogs from the United States. J Vet Intern Med. 2011;25:805-10.

7. Dantas-Torres F, Chomel BB, Otranto D. Ticks and tick-borne diseases: a One Health perspective. Trends Parasitol. 2012;28:437-46.

8. European Scientific Counsel Companion Animal Parasites (ESCCAP) Guideline 05-control of vector-borne diseases in dogs and cats (2nd ed.). 2012. http://www.esccap.org/uploads/docs/ih38c2d6_ESCCA P_Guidelines_GL5_01Oct2012.pdf. Accessed 5 Nov 2017.

9. Beugnet F, Chalvet-Monfray K. Impact of climate change in the epidemiology of vector-borne diseases in domestic carnivores. Comp Immunol Microbiol Infect Dis. 2013;36:559-66.

10. Duscher GG, Leschnik M, Fuehrer HP, Joachim A. Wildlife reservoirs for vector-borne canine, feline and zoonotic infections in Austria. Int J Parasitol Parasites Wildl. 2015:4:88-96.

11. Semenza JC, Menne B. Climate change and infectious diseases in Europe. Lancet Infect Dis. 2009;9:365-75.

12. European Academies Science Advisory Council (EASAC). Climate change and infectious diseases in Europe. 2010. https://www.leopoldina.org/ uploads/tx_leopublication/2010_EASAC_Statement_Climate-chang e-infectious-diseases_ENGL.pdf. Accessed 10 Mar 2010.

13. Cunze S, Koch LK, Kochmann J, Klimpel S. Aedes albopictus and Aedes japonicus - two invasive mosquito species with different temperature niches in Europe. Parasit Vectors. 2016;9:573

14. Otranto D, Capelli G, Genchi C. Changing distribution patterns of canine vector borne diseases in Italy: leishmaniosis vs. dirofilariosis. Parasit Vectors. 2009;2(Suppl. 1):S2.

15. Genchi C, Mortarino M, Rinaldi L, Cringoli G, Traldi G, Genchi M. Changing climate and changing vector-borne disease distribution: the example of Dirofilaria in Europe. Vet Parasitol. 2011:176:295-9.

16. Kovats RS, Valentini R, Bouwer LM, Georgopoulou E, Jacob D, Martin E, et al. Climate change 2014: impacts, adaptation, and vulnerability. Part B: Regional aspects. In: Contribution of working group II to the Fifth Assessment Report of the Intergovernmental Panel on Climate Change. Cambridge: Cambridge University Press; 2014. p. 1267-326.

17. Dantas-Torres F. Climate change, biodiversity, ticks and tick-borne diseases: the butterfly effect. Int J Parasitol Parasites Wildl. 2015;4:452-61.

18. Diakou A, Kapantaidakis E, Tamvakis A, Giannakis V, Strus N. Dirofilaria infections in dogs in different areas of Greece. Parasit Vectors. 2016;9:508.

19. Mylonakis ME, Koutinas AF, Baneth G, Polizopoulou Z, Fytianou A. Mixed Ehrlichia canis, Hepatozoon canis, and presumptive Anaplasma phagocytophilum infection in a dog. Vet Clin Path. 2004;33:249-51.

20. Chochlakis D, Psaroulaki A, Kokkini S, Kostanatis S, Arkalati E, Karagrannaki E, et al. First evidence of Anaplasma infection in Crete, Greece. Report of six human cases. Clin Microbiol Infect. 2009;15(Suppl 2):8-9.

21. Chochlakis D, Papaeustathiou A, Minadakis G, Psaroulaki A, Tselentis Y. A serosurvey of Anaplasma phagocytophilum in blood donors in Crete, Greece. Eur J Clin Microbiol Infect Dis. 2008:27:473-5. 
22. Daniel SA, Manika K, Arvanitidou M, Diza E, Symeonidis N, Antoniadis A. Serologic evidence of human granulocytic ehrlichiosis, Greece. Emerg Infect Dis. 2002;8:643-4

23. Nasereddin A, Salant $H$, Abdeen Z. Feline leishmaniasis in Jerusalem: serological investigation. Vet Parasitol. 2008;158:364-9.

24. Carvalho LFR, de Melo CB, McManus C, Haddad JPA. Use of satellite images for geographical localization of livestock holdings in Brazil. Prev Vet Med. 2012;103:74-7.

25. Pantchev N, Schnyder M, Vrhovec MG, Schaper R, Tsachev I. Current surveys of the seroprevalence of Borrelia burgdorferi, Ehrlichia canis, Anaplasma phagocytophilum, Leishmania infantum, Babesia canis, Angiostrongylus vasorum and Dirofilaria immitis in dogs in Bulgaria. Parasitol Res. 2015;114:117-30.

26. Chandrashekar R, Mainville CA, Beall MJ, O'Connor T, Eberts MD, Alleman AR, et al. Performance of a commercially available in-clinic ELISA for the detection of antibodies against Anaplasma phagocytophilum, Ehrlichia canis, and Borrelia burgdorferi and Dirofilaria immitis antigen in dogs. Am J Vet Res. 2010;71:1443-50.

27. Stillman BA, Monn M, Liu J, Thatcher B, Foster P, Andrews B, et al. Performance of a commercially available in-clinic ELISA for detection of antibodies against Anaplasma phagocytophilum, Anaplasma platys, Borrelia burgdorferi, Ehrlichia canis, and Ehrlichia ewingii and Dirofilaria immitis antigen in dogs. J Am Vet Med Assoc. 2014;245:80-6.

28. Pantchev N, Pluta S, Huisinga E, Nather S, Scheufelen M, Vrhovec MG, et al. Tick-borne diseases (borreliosis, anaplasmosis, babesiosis) in german and austrian dogs: status quo and review of distribution transmission, clinical findings, diagnostics and prophylaxis. Parasitol Res. 2015;114(Suppl. 1):S19-54.

29. Guven E, Avcioglu H, Cengiz S, Hayirli A. Vector-borne pathogens in stray dogs in northeastern Turkey. Vector Borne Zoonotic Dis. 2017;17:610-7.

30. Piantedosi D, Neola B, D'Alessio N, Di Prisco F, Santoro M, Pacifico L, et al. Seroprevalence and risk factors associated with Ehrlichia canis, Anaplasma spp., Borrelia burgdorferi sensu lato, and D. immitis in hunting dogs from southern Italy. Parasitol Res. 2017;116:2651-60.

31. Mircean V, Dumitrache MO, Gyorke A, Pantchev N, Jodies R, Mihalca AD, et al. Seroprevalence and geographic distribution of Dirofilaria immitis and tick-borne infections (Anaplasma phagocytophilum, Borrelia burgdorferi sensu lato, and Ehrlichia canis) in dogs from Romania. Vector Borne Zoonotic Dis. 2012;12:595-604.

32. Mrljak V, Kules J, Mihaljevic Z, Torti M, Gotic J, Crnogaj M, et al. Prevalence and geographic distribution of vector-borne pathogens in apparently healthy dogs in Croatia. Vector Borne Zoonotic Dis. 2017:17:398-408.

33. Hamel D, Shukullari E, Rapti D, Silaghi C, Pfister K, Rehbein S. Parasites and vector-borne pathogens in client-owned dogs in Albania. Blood pathogens and seroprevalences of parasitic and other infectious agents. Parasitol Res. 2016:115:489-99.

34. Mirò G, Montoya A, Roura X, Galvez R, Sainz A. Seropositivity rates for agents of canine vector-borne diseases in Spain: a multicentre study. Parasit Vectors. 2013;6:117

35. Alho AM, Pita J, Amaro A, Amaro F, Schnyder M, Grimm F, et al. Seroprevalence of vector-borne pathogens and molecular detection of Borrelia afzelii in military dogs from Portugal. Parasit Vectors. 2016;9:225.

36. Olano JP Walker DH. Human ehrlichioses. Med Clin North Am. 2002;86:375-92

37. Gardner SL, Holman RC, Krebs JW, Berkelman R, Childs JE. National surveillance for the human ehrlichioses in the United States, 1997-2001, and proposed methods for evaluation of data quality. Ann NY Acad Sci. 2003;990:80-9.

38. Mylonakis ME, Koutinas AF, Leontides LS. Bone marrow mastocytosis in dogs with myelosuppressive monocytic ehrlichiosis (Ehrlichia canis): a retrospective study. Vet Clin Pathol. 2006;35:311-4.

39. Siarkou VI, Mylonakis ME, Bourtzi-Hatzopoulou E, Koutinas AF. Sequence and phylogenetic analysis of the 16S rRNA gene of Ehrlichia canis strains in dogs with clinical monocytic ehrlichiosis. Vet Microbiol. 2007;125:304-12.

40. Mylonakis ME, Day MJ, Siarkou V, Vernau W, Koutinas AF. Absence of myelofibrosis in dogs with myelosuppression induced by Ehrlichia canis infection. J Comp Pathol. 2010;142:328-31.

41. Mylonakis ME, Ceron JJ, Leontides L, Siarkou VI, Martinez S, Tvarijonaviciute $A$, et al. Serum acute phase proteins as clinical phase indicators and outcome predictors in naturally occurring canine monocytic Ehrlichiosis. J Vet Intern Med. 2011;25:811-7.

42. Latrofa MS, Angelou A, Giannelli A, Annoscia G, Ravagnan S, Dantas-Torres F, et al. Ticks and associated pathogens in dogs from Greece. Parasit Vectors. 2017;10:301.

43. Dantas-Torres F, Giannelli A, Figueredo LA, Otranto D. Effects of prolonged exposure to low temperature on eggs of the brown dog tick, Rhipicephalus sanguineus (Latreille, 1806) (Acari: Ixodidae). Vet Parasitol. 2010:171:327-30.

44. Silveira JA, Passos LM, Ribeiro MF. Population dynamics of Rhipicephalus sanguineus (Latrielle, 1806) in Belo Horizonte, Minas Gerais state, Brazil. Vet Parasitol. 2009;161:270-5.

45. Randolph SE, Green RM, Hoodless AN, Peacey MF. An empirical quantitative framework for the seasonal population dynamics of the tick Ixodes ricinus. Int J Parasitol. 2002;32:979-89.

46. McCall JW, Genchi C, Kramer LH, Guerrero J, Venco L. Heartworm disease in animals and humans. Adv Parasitol. 2008;66:193-285.

47. Simon F, Morchon R, Gonzalez-Miguel J, Marcos-Atxutegi C, Siles-Lucas M. What is new about animal and human dirofilariosis? Trends Parasitol. 2009;25:404-9.

48. Genchi C, Rinaldi L, Mortarino M, Genchi M, Cringoli G. Climate and Dirofilaria infection in Europe. Vet Parasitol. 2009;163:286-92.

49. Diakou A. Epidemiological study of dog parasitosis diagnosed by blood and serological examinations. Anima. 2000;8:9-17.

50. Diakou A. The prevalence of canine dirofilariosis in the region of Attiki. JHVMS. 2001;52:152-6.

51. Pampiglione S, Rivasi F, Vakalis N. Human pulmonary dirofilariasis: the first case observed in Greece. Ann Pathol. 2000;20:626-8.

52. Miliaras D, Meditskou S, Kelekis A, Papachristos I. Human pulmonary dirofilariasis: one more case in Greece suggests that Dirofilaria is a rather common cause of coin lesions in the lungs in endemic areas of Europe. Int J Immunopathol Pharmacol. 2010;23:345-8.

53. Simon F, Siles-Lucas M, Morchon R, Gonzalez-Miguel J, Mellado I, Carreton $\mathrm{E}$, et al. Human and animal dirofilariasis: the emergence of a zoonotic mosaic. Clin Microbiol Rev. 2012;25:507-44.

54. Bodker R, Akida J, Shayo D, Kisinza W, Msangeni HA, Pedersen EM, et al. Relationship between altitude and intensity of malaria transmission in the Usambara Mountains, Tanzania. J Med Entomol. 2003:40:706-17.

55. Diakou A, Gewehr S, Kapantaidakis E, Mourelatos S. Can mosquito population dynamics predict Dirofilaria hyperendemic foci? In: E-SOVE 2014 the 19th conference Thessaloniki. 2014. p. 76.

56. Inokuma H, Raoult D, Brouqui P. Detection of Ehrlichia platys DNA in brown dog ticks (Rhipicephalus sanguineus) in Okinawa Island, Japan. J Clin Microbiol. 2000;38:4219-21.

57. Harvey JW, Simpson CF, Gaskin JM. Cyclic thrombocytopenia induced by a Rickettsia-like agent in dogs. J Infect Dis. 1978;137:182-8.

58. Carrade DD, Foley JE, Borjesson DL, Sykes JE. Canine granulocytic anaplasmosis: a review. J Vet Intern Med. 2009;23:1129-41.

59. Dumler JS, Barbet AF, Bekker CP, Dasch GA, Palmer GH, Ray SC, et al. Reorganization of genera in the families Rickettsiaceae and Anaplasmataceae in the order Rickettsiales: unification of some species of Ehrlichia with Anaplasma, Cowdria with Ehrlichia and Ehrlichia with Neorickettsia, descriptions of six new species combinations and designation of Ehrlichia equi and 'HGE agent' as subjective synonyms of Ehrlichia phagocytophila. Int J Syst Evol Microbiol. 2001;51:2145-65.

60. Springer A, Montenegro VM, Schicht S, Pantchev N, Strube C. Seroprevalence and current infections of canine vector-borne diseases in Nicaragua. Parasit Vectors. 2018;11:585.

61. Mylonakis ME, Koutinas AF, Breitschwerdt EB, Hegarty BC, Billinis CD, Leontides LS, et al. Chronic canine ehrlichiosis (Ehrlichia canis): a retrospective study of 19 natural cases. J Am Anim Hosp Assoc. 2004:40:174-84.

62. Psaroulaki A, Koliou M, Chochlakis D, loannou I, Mazeri S, Tselentis Y. Anaplasma phagocytophilum infection in a child. Pediatr Infect Dis J. 2008;27:664-6.

63. Tsiodras S, Spanakis N, Spanakos G, Pervanidou D, Georgakopoulou T, Campos E, et al. Fatal human anaplasmosis associated with macrophage activation syndrome in Greece and the Public Health response. J Infect Public Health. 2017:10:819-23. 
64. Matei IA, Ionica AM, D'Amico G, Corduneanu A, Daskalaki AA, Lefkaditis M, et al. Altitude-dependent prevalence of canine granulocytic anaplasmosis in Romania. Vector Borne Zoonotic Dis. 2017;17:147-51.

65. Barbour AG, Hayes SF. Biology of Borrelia species. Microbiol Rev. 1986;50:381-400.

66. Duncan AW, Correa MT, Levine JF, Breitschwerdt EB. The dog as a sentinel for human infection: Prevalence of Borrelia burgdorferi C6 antibodies in dogs from southeastern and mid-Atlantic states. Vector Borne Zoonotic Dis. 2004;4:221-9.

67. Stamouli M, Totos G, Braun HB, Michel G, Gizaris V. Very low seroprevalence of Lyme borreliosis in young Greek males. Eur J Epidemiol. 2000;16:495-6.
68. Antoniou M, Economou I, Wang X, Psaroulaki A, Spyridaki I, Papadopoulos $B$, et al. Fourteen-year seroepidemiological study of zoonoses in a Greek village. Am J Trop Med Hyg. 2002;66:80-5.

69. Santino I, Dastoli F, Sessa R, DelPiano M. Geographical incidence of infection with Borrelia burgdorferi in Europe. Panminerva Med. 1997;39:208-14.

\section{Publisher's Note}

Springer Nature remains neutral with regard to jurisdictional claims in published maps and institutional affiliations.
Ready to submit your research? Choose BMC and benefit from:

- fast, convenient online submission

- thorough peer review by experienced researchers in your field

- rapid publication on acceptance

- support for research data, including large and complex data types

- gold Open Access which fosters wider collaboration and increased citations

- maximum visibility for your research: over 100M website views per year

At BMC, research is always in progress.

Learn more biomedcentral.com/submissions 